\title{
Implementasi Load Balancing menggunakan Teknologi EtherChanne/ pada Jaringan LAN
}

\author{
KUKUH NUGROHO, MUHAMAD SYAMSUL FALLAH
}

\author{
Teknik Telekomunikasi IT Telkom Purwokerto \\ Email : kukuh@ittelkom-pwt.ac.id
}

Received 12 Juli 2018 | Revised 29 Agustus 2018 | Accepted 26 September 2018

\begin{abstract}
ABSTRAK
Jumlah pengguna yang meningkat merupakan salah satu penyebab menurunnya kualitas jaringan jika hanya menggunakan ukuran bandwidth yang sama. Sebagai contoh pada implementasi jaringan kampus, jaringan LAN antar gedung yang berbeda biasanya dihubungkan dengan menggunakan perangkat switch. Penurunan performansi jaringan pada jaringan tersebut akibat pertambahan jumlah pengguna bisa diatasi dengan menggunakan konsep load balancing dengan memanfaatkan teknologi EtherChannel. Implementasi teknologi tersebut dapat menggunakan dua pilihan protokol yaitu PAgP dan LACP. Penelitian ini bertujuan untuk menguji performansi jaringan yang menerapkan konsep load balancing dengan menggunakan protokol PAgP dan LACP. Skenario pengujian menggunakan konsep client-server, dimana aplikasi server yang digunakan adalah FTP untuk implementasi layanan pertukaran data dan penggunaan software VLC untuk implementasi layanan video streaming. Pada penggunaan layanan FTP dengan protokol PAgP dihasilkan nilai delay 42\% lebih baik dibandingkan dengan LACP. Begitupula untuk nilai throughput, penggunaan protokol PAgP masih lebih baik $10 \%$ dibandingkan dengan $\angle A C P$.
\end{abstract}

Kata kunci: LAN, Load balancing, Etherchannel, PAgP, LACP

\begin{abstract}
The increasing number of users is one cause of declining network performance if only use on the same bandwidth value. For example, in the implementation on the campus network, LAN among different building is usually connected using a switch. The decreasing of network performance on that network due to the increasing of the number of users which can be overcome by using a load balancing concept with EtherChannel technology utilization. The implementation of that technology uses two protocols, namely PAgP and LACP. This research intends to test the network performance by applying the load balancing concept using both PAgP and $\angle A C P$ protocols. The experiment scenarios used a client-server concept, where the implemented application server is FTP for exchanging data services and VLC software for implementing video streaming services. In the use of FTP services with using PAgP protocol showed a delay value of $42 \%$ better than $L A C P$. The same with throughput value, the use of PAgP protocol still better $10 \%$ than LACP.
\end{abstract}

Keywords: LAN, Load balancing, Etherchannel, PAgP, LACP 
Implementasi Load Balancing menggunakan Teknologi EtherChanne/pada Jaringan LAN

\section{PENDAHULUAN}

Penggunaan teknologi dalam jaringan komputer lebih difungsikan agar performansi jaringan yang digunakan untuk proses transfer data lebih meningkat (Komputer, 2012). Dalam jaringan LAN (Local Area Network) skala kecil dengan jumlah pengguna yang relatif sedikit, penggunaan bandwidth kecil mungkin tidak berpengaruh dengan tingkat kepuasan pengguna. Akan tetapi, seiring dengan pertambahan jumlah pengguna dalam jaringan LAN tersebut, maka perlu adanya proses pemetaan ulang jaringan, terutama dalam hal penggunaan bandwidth. Masalah ini sering dijumpai pada kebanyakan jaringan LAN, terutama pada implementasi jaringan kampus. Penambahan jumlah student body mahasiswa ikut penambah masalah dalam hal buruknya performansi jaringan apabila tidak diikutsertakan dengan penambahan jumlah bandwidth. Selain dengan cara meningkatkan ukuran bandwidth, salah satu solusi yang bisa digunakan adalah dengan menggunakan teknologi yang terdapat dalam perangkat switch yaitu EtherChannel. Konsep yang digunakan dalam teknologi EtherChannel adalah dengan menggabungkan beberapa jalur fisik menjadi satu jalur saja, akan tetapi sifatnya adalah logic (Nugroho, 2017).

Beberapa penelitian telah dilakukan untuk meneliti penggunaan teknologi EtherChannel maupun mengenai konsep load balancing yang disediakan oleh teknologi tersebut. Rohmat Tulloh (Tulloh, 2017) melakukan penelitian terhadap penggunaan teknologi EtherChannel namun diimplementasikan dalam jaringan SDN dengan menggunakan controller Ryu. Protokol yang digunakan adalah LACP. Dari hasil penelitian diperoleh data bahwa penggunaan teknologi EtherChannel memberikan perbaikan performansi jaringan dilihat dari parameter throughput, jitter, maupun packet loss. Misalnya jika dilihat dari sisi throughput diketahui bahwa penggunaan teknologi EtherChannel memberikan perbaikan sebesar 22,53\% dibandingkan dengan konsep jaringan yang tidak menggunakan teknologi EtherChannel. Konsep topologi jaringan yang digunakan pada penelitian tersebut adalah dengan melakukan penggabungan sebanyak empat buah jalur fisik.

Konsep link-aggregation juga bisa diimplementasikan dengan menambahkan mekanisme keamanan. Penggabungan beberapa jalur yang digunakan untuk menghubungkan antar dua perangkat dapat dilakukan jika proses autentikasi antar kedua perangkat tersebut berhasil. Proses penggabungan jalur seperti ini, selain meningkatkan performansi jaringan juga dapat menambah sisi keamanan jaringan. Penelitian yang dilakukan oleh Amin (Amin, 2014) tentang implementasi konsep link-aggregation dengan menambahkan tingkat keamanan dan penggunaan konsep jaringan yang bersifat hirarki menunjukkan hasil bahwa penggunaan konsep tersebut masih dapat meningkatkan parameter nilai throughput jaringan. Studi kasus yang digunakan pada penelitian tersebut adalah jaringan yang terdapat pada STMIK dan Politeknik Palcomtech, Palembang. Metode penelitian yang digunakan adalah PPDIOO (Prepare, Plan, Design, Implement, Operate, and Optimize).

Perbaikan dari sisi performansi jaringan jika digunakan teknologi EtherChannel juga diperkuat oleh penelitian yang dilakukan oleh SysKonnect (SysKonnect, 2002) tentang konsep linkaggregation menggunakan standarisasi IEEE 802.3ad. Konsep link-aggregation adalah menggabungkan beberapa jalur menjadi satu jalur. Konsep ini sama hal dengan konsep penggunaan teknologi EtherChannel. Pada penelitian tersebut dinyatakan bahwa penggunaan konsep link-aggregation dapat menambah ukuran bandwidth saluran dan juga mampu menyediakan fasilitas load balancing.

Pada penilitian ini lebih difokuskan pada penggunaan teknologi EtherChannel dimana pilihan protokol yang digunakan adalah PAgP (Port Aggregation Protoco) dan LACP (Link Aggregation Control Protocol). Tujuan dari penggunaan kedua protokol tersebut adalah untuk 
membandingkan performansi jaringan jika digunakan pilihan protokol PAgP buatan dari Cisco dan LACP yang dibuat oleh IEEE. Sifat penggunaan protokol PAgP adalah tertutup, artinya hanya perangkat produk dari Cisco saja yang bisa menggunakan protokol tersebut. Berbeda dengan penggunaan protokol LACP yang semua produk switch dari vendor manapun bisa menggunakan-nya. Manfaat dari penelitian ini adalah untuk mengetahui seberapa besar peningkatan performansi jaringan jika dimanfaatkan teknologi EtherChannel dengan menggunakan dua pilihan protokol yaitu PAgP dan LACP. Layanan yang digunakan dalam penelitian ini adalah FTP dan video streaming. Penggunaan kedua layanan tersebut tidak hanya diimplementasikan pada jaringan fisik, akan tetapi juga dengan menerapkan teknologi jaringan virtualisasi. Penelitian yang dilakukan oleh Djomi (Djomi, 2018) tentang penerapan teknologi jaringan virtualisasi dengan menggunakan teknologi containers. Layanan yang digunakan pada penelitian tersebut juga sama yaitu FTP dan video streaming.

\section{METODOLOGI PENELITIAN}

Metode penelitian yang digunakan adalah secara eksperimental di laboratorium. Tahapan awal penelitian dimulai dari proses studi literatur yang dilakukan dengan mencari referensi penelitian sebelumnya yang terkait dengan konsep link-aggregation atau load balancing melalui jurnal atau prosiding yang telah dilakukan sebelumnya. Dalam hal ini referensi yang berkaitan dengan penggunaan teknologi EtherChannel dengan menggunakan protokol PAgP (Port Aggregation Protocol) dan LACP (Link Aggregation Control Protocol). Tahapan selanjutnya adalah merancang topologi jaringan yang digunakan dalam proses penelitian. Dalam merancang topologi jaringan sebagai sistem yang diuji yaitu menggunakan konsep linkaggregation. Jumlah link atau jalur yang akan digabungkan pada saat proses penelitian menggunakan maksimal 8 jalur. Hal ini diperkuat setelah melakukan studi literatur tentang maksimal jalur yang bisa digabung oleh perangkat switch produk dari Cisco adalah sebanyak 8 jalur (Community, 2007).

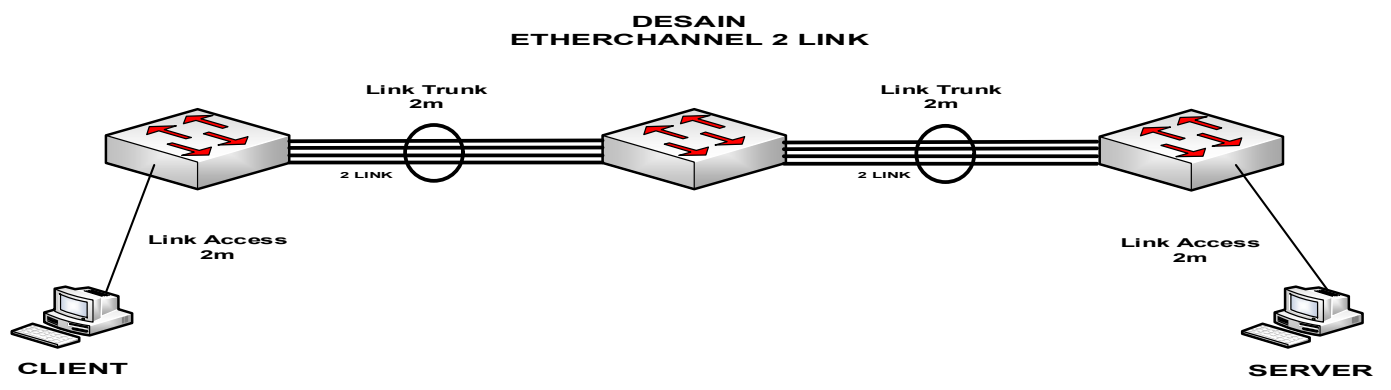

Gambar 1. Desain topologi jaringan

Gambar 1 di atas menjelaskan topologi jaringan yang digunakan pada proses penelitian. Perangkat switchyang digunakan sebanyak tiga buah. Hal ini disesuaikan dengan ketersediaan jumlah perangkat switch Cisco (Catalyst) di laboratorium tempat uji jaringan. Antar switch dihubungkan dengan menggunakan kabel UTP cat6 dengan panjang 2 meter. Begitupula antara jarak switch dengan komputer, sehingga perkiraan jarak total antar kedua komputer client dan server adalah sebesar 8 meter. Dengan semakin panjang jarak kabel yang menghubungkan antar dua komputer, mengakibatkan terjadinya penurunan performansi jaringan, terutama terhadap peningkatan nilai delay (latency) dan adanya paket yang hilang (packet loss). Jarak maksimal panjang kabel UTP Cat6 yang dapat digunakan agar masih didapatkan nilai packet loss sebesar 0\% adalah 256 meter (Nugroho, K, 2017). Walaupun penggunaan panjang kabel 8 meter saat pengujian jaringan tidak sebanding dengan panjang 
Implementasi Load Balancing menggunakan Teknologi EtherChanne/pada Jaringan LAN

kabel 256 meter, namun dengan menggunakan panjang kabel tersebut sudah dapat merepresentasikan akan adanya peningkatan nilai delay dibandingkan dengan hanya menggunakan panjang kabel kurang dari 8 meter. Penurunan performansi jaringan akibat jarak kabel penghubung dapat ditingkatkan dengan menggunakan metode penggabungan jalur (link-aggregation) antar dua perangkat switch. Sesuai dengan penjelasan Gambar 1 di atas, proses load balancing terjadi antar tiga perangkat switch yang terhubung. Jalur yang menghubungkan antar perangkat switch dinamakan sebagai jalur trunk. Konsep linkaggregation disini adalah dengan menggabungkan beberapa jalur trunk tersebut, dimana maksimal jalur yang digunakan adalah sebanyak 8 jalur. Walaupun penggunaan skenario uji jaringan sesuai dengan Gambar 1 di atas dapat meningkatkan performansi jaringan, namun jika dilihat dari sisi tingkat keamanan masih kurang. Data yang dipertukarkan antar dua komputer yang dihubungkan dengan hanya menggunakan perangkat switch akan rentang untuk diambil dan dibaca oleh pengguna yang lain. Hal ini dikarenakan kedua komputer tersebut masih terletak pada wilayah broadcast atau alamat network yang sama.

Perangkat yang digunakan terdiri dari perangkat keras (hardware) dan perangkat lunak (software). Perangkat keras yang digunakan pada penelitian ini diantaranya adalah 3 unit switch Cisco seri 2950 Catalyst, kabel UTP Cat5 sebagai media penghubung antara switch dan komputer, kabel console sebagai media untuk konfigurasi switch awal, serta 2 unit PC dengan spesifikasi Intel (R) Core(TM) i3-4005U CPU @1.70GHz 1.70GHz, RAM = 4GB. Adapun perangkat lunak yang digunakan pada penelitian ini diantaranya adalah software Putty untuk konfigurasi perangkat switch, USB merek Aten untuk menghubungkan antara switch dengan laptop, Filezilla untuk mengaktifkan server FTP, VLC media player untuk implementasi layanan video streaming, serta software wireshark untuk menghitung parameter performansi jaringan seperti delay, packet loss, jitter, dan throughput.

Konsep jaringan yang digunakan untuk proses uji performansi jaringan adalah client-server. Terdapat dua layanan yang digunakan yaitu file transfer dengan mengaktifkan serverFTP dan video streaming dengan menggunakan bantuan software VLC media player. Nantinya PC client akan mengakses layanan yang diaktifkan di server baik itu FTP maupun video streaming. Pada saat yang bersamaan, software wireshark diaktifkan. Penggunaan software tersebut adalah untuk mengetahui nilai parameter pengukur dari performansi jaringan. Pengukuran performansi jaringan dilakukan ketika konsep link-aggregation sudah diaktifkan pada jalur trunk. Pilihan protokol yang digunakan pada proses penelitian ada dua yaitu PAgP dan LACP. Terdapat beberapa skenario pengukuran yaitu ketika hanya menggunakan dua jalur saja yang digabungkan, tiga jalur, empat jalur, lima jalur, enam jalur, tujuh jalur, sampai delapan jalur. Masing-masing skenario pengujian menghasilkan nilai parameter performansi jaringan yang berbeda-beda.

\subsection{Parameter Performansi Jaringan}

Pengukuran unjuk kerja jaringan dilakukan dengan menggunakan bantuan software wireshark. Terdapat empat parameter yang diamati saat proses pengujian jaringan yaitu delay, jitter, packet loss, dan throughput.

\subsubsection{Delay}

Delay adalah waktu yang dibutuhkan oleh sebuah paket untuk bisa sampai ke perangkat tujuan dari pertama kali bit pada paket tersebut dikirimkan oleh perangkat pengirim (Forouzan, 2013). Waktu tunda ini menyebabkan adanya keterlambatan paket yang dikirim untuk sampai pada penerima. Perhitungan untuk mengetahui nilai delay dari pengirim menuju penerima menggunakan Persamaan (1). 


$$
\operatorname{Delay}(\mathrm{sec})=\frac{\text { Waktu antara paket } 1 \text { dan terakhir }}{\sum \text { total paket }}
$$

Pada saat software wireshark diaktifkan, software tersebut akan menangkap semua paket yang lewat dalam jaringan. Perhitungan nilai delay dilakukan hanya pada paket yang berasal dari komunikasi antara client dan server. Karena pada skenario topologi jaringan tidak menggunakan background traffic, maka paket yang beredar dalam jaringan hanyalah paket yang berasal dari kedua komputer tersebut. Persamaan (1) menjelaskan cara mendapatkan nilai delay dengan menggunakan software wireshark yaitu waktu antara pengiriman paket pertama sampai paket terakhir dibagi dengan jumlah paket yang diterima. Hasil dari perhitungan nilai delay akan dibandingkan dengan standarisasi nilai delay yang dikeluarkan oleh ITU-T G (ITU-T, 2003).

Tabel 1. Standarisasi nilai delay dari ITU-T G.114

\begin{tabular}{|c|c|c|}
\hline \multirow{2}{*}{$\begin{array}{c}\text { Delay } \\
\text { (Latency) }\end{array}$} & Category & Delay \\
\cline { 2 - 3 } Standard & Good & $0-150 \mathrm{~ms}$ \\
\cline { 2 - 3 } & Medium & $150-400 \mathrm{~ms}$ \\
\cline { 2 - 3 } & Poor & $>400 \mathrm{~ms}$ \\
\hline
\end{tabular}

Tabel 1 menjelaskan standarisasi nilai delay. Hasil perhitungan nilai delay dikatakan baik apabila nilai-nya diantara 0 sampai 150 ms, sedangkan untuk kategori sedang yaitu antara 150 sampai $400 \mathrm{~ms}$. Nilai tersebut dijadikan sebagai acuan untuk menilai hasil perhitungan saat proses pengujian jaringan.

\subsubsection{Jitter}

Jitter adalah variasi delay (Forouzan, 2013). Paket yang dikirimkan oleh perangkat pengirim akan sampai ke perangkat penerima dengan waktu kedatangan yang berbeda-beda. Rata-rata variasi waktu antar kedatangan paket dimanakan sebagai jitter. Pengertian dari jitter akan berhubungan dengan nilai delay. Variasi delay antar kedatangan atau pengiriman paket akan berpengaruh terdapat nilai jitter. Nilai delay besar disertai nilai jitter besar dapat dikatakan performansi jaringan dalam keadaan sangat buruk. Kondisi terbaik adalah jika didapatkan nilai delay dan jitter kecil. Hal ini menandakan performansi jaringan dalam keadaan sangat baik. Pengukuran nilai jitter menggunakan Persamaan (2).

$$
\operatorname{Jitter}(\mathrm{sec})=\frac{\sum \text { delay-variasi }}{\sum \text { paket terima-paket kirim }}
$$

Hasil pengukuran nilai jitter akan dibandingkan dengan standarisasi jitter yang dikeluarkan oleh ITU-G.114 untuk mengetahui kualitas dari jaringan yang diamati.

Tabel 2. Standarisasi nilai jitter dari ITU-T G.114

\begin{tabular}{|c|c|c|}
\hline Jitter & Category & Jitter \\
\cline { 2 - 3 } Standard & Good & $0-20 \mathrm{~ms}$ \\
\cline { 2 - 3 } & Medium & $20-50 \mathrm{~ms}$ \\
\cline { 2 - 3 } & Poor & $>50 \mathrm{~ms}$ \\
\hline
\end{tabular}

Standarisasi nilai jittermasih lebih rendah dibandingkan nilai delay. Sebagai contoh untuk jitter kategori bagus terletak di antara rentang nilai 0 sampai $20 \mathrm{~ms}$. Nilai jitter berada di rentang nilai sedang ada pada nilai 20 sampai 50 ms. 


\subsubsection{Throughput}

Throughput merupakan sebuah ukuran yang menyatakan nilai bandwidth sebenarnya yang diterima oleh sebuah perangkat (Forouzan, 2013). Rumus untuk menghitung nilai throughput pada saat penelitian menggunakan Persamaan (4).

$$
\text { Throughput }=\frac{\sum \text { ukuran paket kirim }}{\text { waktu pengiriman paket }} \text { bps }
$$

Dari Persamaan (4) nilai throughput merupakan hasil bagi dari jumlah total ukuran data yang dikirimkan dengan waktu total pengiriman data.

\subsection{Implementasi Sistem}

Pada penelitian ini digunakan perangkat switch asli yaitu tiga buah Catalyst seri 2950. Perangkat tersebut dihubungkan secara langsung seperti yang terlihat pada keterangan Gambar 1. Jalur trunk yang menghubungkan antar switch akan digabung dengan cara mengimplementasikan teknologi EtherChannel. Pilihan protokol yang digunakan adalah PAgP dan LACP.

Sebelum dilakukan proses konfigurasi, terlebih dahulu memastikan bahwa pada jalur trunk, kecepatan transfer data yang digunakan oleh interface Ethernet sama. Pada saat implementasi jaringan, tipe Ethernet yang digunakan pada jalur trunk adalah FastEthernet dengan kecepatan 100 Mbps. Hal ini dikarenakan salah satu syarat port switch bisa digabung adalah kecepatan transfer data antar port switch tersebut harus sama. Maksimal jalur saat melakukan proses pengujian adalah 8 jalur (port). Setelah memastikan kecepatan dari port switch, berikutnya adalah memastikan wilayah VLAN yang digunakan oleh masing-masing port adalah sama. Pada saat pengujian digunakan wilayah VLAN dengan nomer 1 (VLAN 1).

\subsubsection{Konfigurasi PAgP}

Dalam menggabungkan port switch, protokol PAgP akan melakukan proses negoisasi dengan port switch lawan. Proses tersebut dilakukan dengan cara mempertukarkan paket antar perangkat switch dan tipe paket tersebut tergantung dari protokol yang digunakan. Ketika protokol PAgP diaktifkan, pilihan berikutnya adalah menentukan mode dari port switch tersebut. Pilihan mode yang digunakan ada dua yaitu "desirable" dan "auto". Port switch yang diaktifkan mode "desirable" akan aktif dalam mengirimkan paket negoisasi ke perangkat switch lawan. Berbeda dengan mode "auto" yang memiliki sifat menunggu paket negoisasi dari perangkat switch lawan. Proses penggabungan port switch akan berhasil jika kombinasi mode yang digunakan benar. Misalnya memilih mode interface yang berbeda di kedua ujung yang saling terhubung yaitu mode "desirable" dan "auto".

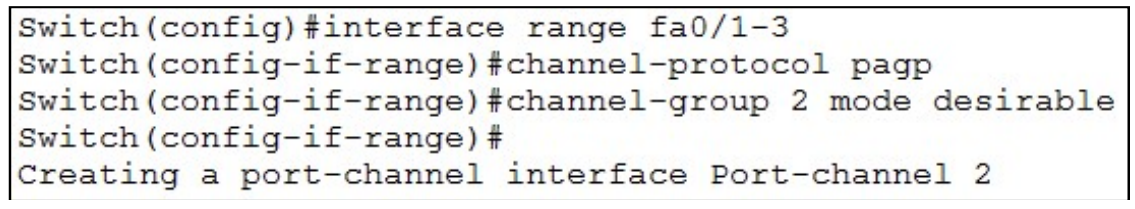

\section{Gambar 2. Konfigurasi PAgP}

Gambar 2 di atas menjelaskan cara mengkonfigurasi teknologi EtherChannel menggunakan protokol PAgP. Nomer grup yang digunakan pada saat pengujian yaitu 2. Grup tersebut menandakan kumpulan interface atau port yang telah digabungkan. Grup harus diberikan penanda sama seperti identitas port fisik switch seperti FastEthernet0/1. Setelah diaktifkan protokol PAgP kemudian disebutkan mode port EtherChannel. Mode port switch yang digunakan antara switch yang saling terhubung digunakan mode "desirable" dan "auto". Untuk 
Nugroho, dkk

membuat mode "auto" perintah yang digunakan sama hanya mengubah mode "desirable" menjadi "auto".

\subsubsection{Konfigurasi LACP}

Protokol LACP menggunakan konsep yang sama seperti PAgP. Protokol tersebut akan menggabungkan port switch secara logic. Perbedaan hanya terletak pada mode port yang digunakan. Pilihan mode port yang digunakan oleh protokol LACP terdapat mode "active" dan "passive". Sebelum port switch yang telah digabungkan antara kedua switch, proses negoisasi harus dilakukan antara kedua switch tersebut.

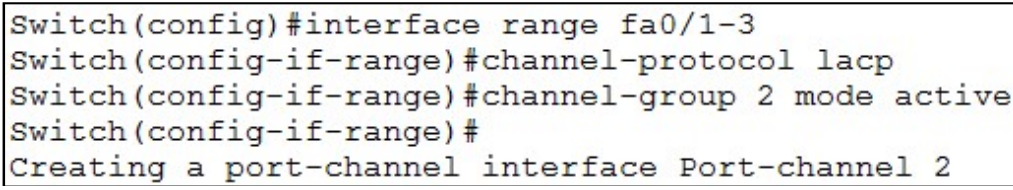

\section{Gambar 3. Konfigurasi LACP}

Konfigurasi EtherChanne/ menggunakan protokol LACP sama seperti dalam mengaktifkan protokol PAgP. Perbedaan utama hanya terletak pada penggunaan mode port-nya. Gambar 3 di atas menjelaskan hasil konfigurasi dimana mode yang digunakan adalah "active". Agar proses negoisasi berhasil dilakukan maka mode dari port lawan harus sama-sama "active" atau "passive". Terakhir dari langkah konfigurasi adalah mengaktifkan mode trunk pada kedua port switch hasil dari proses penggabungan antara beberapa port.

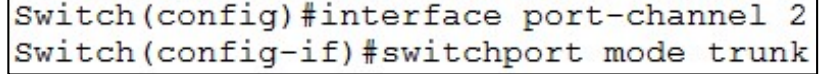

\section{Gambar 4. Konfigurasi mode trunk}

Gambar 4 menjelaskan cara mengaktifkan mode trunk pada interface port-channel. Interface tersebut merupakan interface logic dari dari beberapa interface fisik dalam perangkat switch.

\subsection{Implementasi Sistem}

Pengujian sistem dilakukan setelah menyiapkan skema topologi jaringan dan melakukan proses instalasi perangkat. Terdapat beberapa software yang digunakan untuk melakukan pengujian sistem seperti Wireshark, VLC, dan FileZilla. Software Wireshark digunakan untuk melakukan proses perhitungan nilai delay, jitter, throughput, dan packet loss. Pemasangan software tersebut ada pada komputer client dan server. Implementasi serverdilakukan dengan menggunakan software FileZilla untuk proses transfer file dengan cara mengaktifkan server FTP. Sedangkan software VLC digunakan untuk mengimplementasikan skenario video streaming.

Skenario awal dilakukan dengan menjalankan aplikasi transfer file. Komputer server diaktifkan FTP di dalam software paket-an yang terdapat dalam FileZilla. Ukuran file yang dipertukarkan dibuat bervariasi dimulai dari 20 MByte, 30 MByte, 50 MByte, 70 MByte dan 100 MByte. Proses pengambilan data tidak bisa langsung didapatkan dari software Wireshark, akan tetapi hasil yang didapatkan dari software tersebut harus diubah ke dalam format ".csv" agar bisa dibaca oleh software Microsoft Excel. Hasil dari pengolahan dari software Ms. Excel dihasilkan empat parameter pengukur kinerja sistem yaitu delay, jitter, packet loss, dan throughput. Pengujian berikutnya yaitu dengan menjalankan aplikasi video streaming.

Sama seperti pengujian data yang sifat-nya non-realtime seperti pertukaran file dengan menggunakan protokol FTP, pengujian video streaming juga menggunakan acuan ukuran dari file video yang dipertukarkan antara komputer client dan server. Terdapat lima ukuran file video yang digunakan dalam proses pengujian yaitu 20 MByte, 30 MByte, 50 MByte, 70 MByte 
dan 100 Mbyte, sama seperti pengujian dengan menggunakan layanan transfer file. Software untuk melakukan uji sistem masih sama yaitu Wireshark. Pengamatan dilakukan dengan menggunakan perintah "udp. port $==1234$ " pada software Wireshark untuk mendapatkan data hasil video streaming.

udp. port $==1234$

Gambar 5. Proses filtering di Wireshark

\begin{tabular}{|c|c|c|c|c|c|}
\hline \multicolumn{6}{|c|}{\begin{tabular}{|l|l|} 
& udp.port $==1234$ \\
\end{tabular}} \\
\hline No. & & Time & Source & Destination & Protocol \\
\hline+ & 2070 & 46.603289 & $172 \cdot 16 \cdot 0 \cdot 254$ & 192.168 .20 .10 & MPEG TS \\
\hline 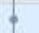 & 2071 & 46.604168 & $172.16 \cdot 0 \cdot 254$ & 192.168 .20 .10 & MPEG-1 \\
\hline & 2211 & 48.542420 & $172.16 \cdot 0.254$ & 192.168 .20 .10 & MPEG TS \\
\hline & 2212 & 48.543574 & $172.16 \cdot 0.254$ & 192.168 .20 .10 & MPEG TS \\
\hline & 2213 & 48.543580 & $172.16 \cdot 0.254$ & 192.168 .20 .10 & MPEG TS \\
\hline & 2214 & 48.547962 & $172.16 \cdot 0.254$ & 192.168 .20 .10 & MPEG TS \\
\hline & 2215 & 48.547970 & $172 \cdot 16 \cdot 0 \cdot 254$ & 192.168 .20 .10 & MPEG TS \\
\hline & 2216 & 48.547974 & $172.16 \cdot 0.254$ & 192.168 .20 .10 & MPEG TS \\
\hline & 2217 & 48.547977 & $172.16 \cdot 0.254$ & 192.168 .20 .10 & MPEG TS \\
\hline & 2218 & 48.547980 & $172.16 \cdot 0.254$ & 192.168 .20 .10 & MPEG TS \\
\hline & 2219 & 48.547983 & $172.16 \cdot 0 \cdot 254$ & 192.168 .20 .10 & MPEG TS \\
\hline & 2220 & 48.548854 & $172.16 \cdot 0.254$ & 192.168 .20 .10 & MPEG TS \\
\hline & 2221 & 48.549758 & $172.16 \cdot 0.254$ & 192.168 .20 .10 & MPEG TS \\
\hline & 2222 & 48.549764 & $172.16 \cdot 0.254$ & 192.168 .20 .10 & MPEG TS \\
\hline & 2223 & 48.551207 & $172.16 \cdot 0.254$ & 192.168 .20 .10 & MPEG TS \\
\hline & 2224 & 48.551215 & $172.16 \cdot 0.254$ & 192.168 .20 .10 & MPEG TS \\
\hline & 2225 & 48.553654 & $172.16 \cdot 0.254$ & 192.168 .20 .10 & MPEG TS \\
\hline & 2226 & 48.553662 & $172.16 \cdot 0.254$ & 192.168 .20 .10 & MPEG TS \\
\hline & 2227 & 48.553665 & $172.16 \cdot 0.254$ & 192.168 .20 .10 & MPEG TS \\
\hline
\end{tabular}

Gambar 6. Hasil filtering udp.port $=\mathbf{1 2 3 4}$

Penggunaan perintah filtering pada Gambar 5 menghasilkan proses komunikasi hanya antara komputer client dan server saat dijalankan aplikasi video streaming seperti yang terlihat pada keterangan Gambar 6. Di sisi server diaktifkan software VLC untuk menjalankan layanan video streaming, sehingga untuk menampilkan komunikasi antara client dengan server yang diaktifkan software tersebut digunakan nomer port 1234 dengan protokol layer transportyang digunakan adalah UDP (User Datagram Protocol). Penggunaan layanan video streaming nantinya digunakan sebagai data pembanding dari hasil uji sistem terhadap data yang sifatnya non-realtime seperti proses transfer file.

\section{HASIL PENGUJIAN}

Topologi jaringan yang digunakan sebagai sistem uji terlihat pada keterangan Gambar 1. Pada topologi jaringan tersebut akan digunakan dua pilihan protokol yaitu PAgP dan LACP sebagai sebagai protokol untuk mengimplementasikan teknologi EtherChannel. Masing-masing protokol akan diujikan pada skema topologi jaringan seperti yang terlihat pada Gambar 1 . Perbedaan yang mendasar dari skema dasar topologi jaringan yang digunakan untuk proses uji sistem adalah pada penggunaan jalur yang akan digabungkan. Jumlah jalur yang digabungkan dimulai dari penggunaan 2, 3, 4, 5, 6, 7, dan 8 jalur. Masing-masing jalur akan dilihat performansi jaringan-nya dengan menggunakan pilihan protokol yang berbeda. Terdapat tiga parameter yang digunakan untuk melihat performansi jaringan yaitu delay, jitter, dan throughput. Sistem diuji dengan mengalirkan trafik data, dimana layanan yang digunakan adalah berupa proses transfer data dan video streaming. 


\subsection{Pengujian Parameter Delay dan Jitter \\ 3.1.1 Layanan Transfer Data}

Pada pengujian ini masih menggunakan skema topologi jaringan pada Gambar 1. Jaringan akan diuji dengan melakukan pembebanan berupa proses transfer data. Di sisi server diaktifkan software FileZilla yang digunakan untuk mengaktifkan aplikasi serverFTP. Kemudian pada server tersebut diberikan file dengan ukuran yang bervariasi mulai dari 20 Mbyte, 30 Mbyte, 50 Mbyte, 70 Mbyte, dan 100 Mbyte untuk nantinya file tersebut akan diakses oleh komputer client. Pada masing-masing proses transfer file menggunakan ukuran yang berbedabeda. Kemudian topologi jaringan yang sudah diterapkan mekanisme link-aggregation akan diuji menggunakan parameter delay, jitter, dan throughput.

Parameter awal yang diuji adalah delay. Proses transfer file dilakukan antara komputer client dan server. Waktu proses pengiriman data dari komputer server sampai ke client akan dihitung. Skenario proses pertukaran data menggunakan ukuran file yang berbeda-beda. File tersebut tersimpan dalam server FTP, kemudian diunduh oleh komputer client. Pengujian dilakukan dengan menggunakan jumlah link yang digabung berbeda-beda, dimulai dari 2 jalur, 3 jalur, sampai 8 jalur.



Gambar 7. Delay layanan transfer file PAgP

Proses pengambilan data dimulai dari penggabungan 2 jalur. Proses penggabungan jalur tersebut dilakukan pada jalur trunk. Gambar 7 di atas memperlihatkan hasil pengujian nilai delay disaat layanan yang digunakan adalah berupa proses pertukaran data (file) dari komputer server ke client. Nilai delay terkecil terlihat jika jumlah jalur yang digabungkan maksimal yaitu 8 jalur dan yang terbesar yaitu pada penggunaan 2 jalur. Hal ini terlihat bahwa dengan menggabungkan jumlah jalur yang semakin banyak, nilai delay yang dihasilkan juga semakin kecil. Dengan menggabungkan jalur, beban trafik data akan dibagi, sehingga waktu yang dibutuhkan untuk mengirimkan paket agar bisa sampai ke tujuan juga semakin kecil. Dari penjelasan grafik pada gambar 7 terlihat juga bahwa dengan memperbesar ukuran paket yang dipertukarkan antara client dan server FTP, nilai delay yang dihasilkan juga semakin besar.

Pengaruh penggunaan teknologi EtherChannel sangat berpengaruh terhadap perbaikan performansi jaringan. Hal ini bisa dilihat dari hasil keluaran uji parameter delay dengan menggunakan topologi jaringan pada keterangan Gambar 7 di atas. Misalnya pada proses pertukaran data dengan menggunakan ukuran 20 Mbyte. Pada saat menggunakan jumlah jalur yang digabung sebanyak 2 jalur diperoleh nilai delay sebesar 2,23 ms. Nilai tersebut masih dikatakan baik menurut standar yang dikeluarkan oleh ITU-T G.114. Kemudian ketika jumlah jalur yang digabung ditambah menjadi 3 jalur, terdapat penurunan nilai delay sebesar 1,62 
ms. Perbaikan nilai delay dengan menambah jumlah jalur yang digabung pada kasus ini adalah sebesar 38\%. Ketika jumlah jalur yang digabung ditambah menjadi 4 jalur, juga terjadi penurunan nilai delay yaitu 1,01 ms. Artinya terdapat perbaikan performansi jaringan sebesar $60 \%$. Dari grafik yang terlihat pada keterangan Gambar 7, nilai delay akan menurun dengan menambahkan jumlah jalur yang digabung. Seperti contoh pada penggunaan ukuran data 20 Mbyte. Dengan menggunakan ukuran data tersebut diketahui bahwa rata-rata prosentase peningkatan performansi jaringan sekitar 47\%. Begitupula untuk hasil uji dengan menggunakan ukuran data yang lain. Dengan memperbesar ukuran dari data yang digunakan, dihasilkan penurunan nilai dari prosentase perbaikan performansi jaringan. Nilai rata-rata prosentase perbaikan performansi jaringan berturut-turut untuk penggunaan ukuran data sebesar 30 Mbyte, 50 Mbyte, 70 Mbyte, dan 100 Mbte adalah 42\%, 21\%, 16\%, dan 4\%. Hal ini menandakan bahwa dengan semakin besar ukuran data yang digunakan, nilai kenaikan prosentase perbaikan performansi jaringan juga semakin kecil.

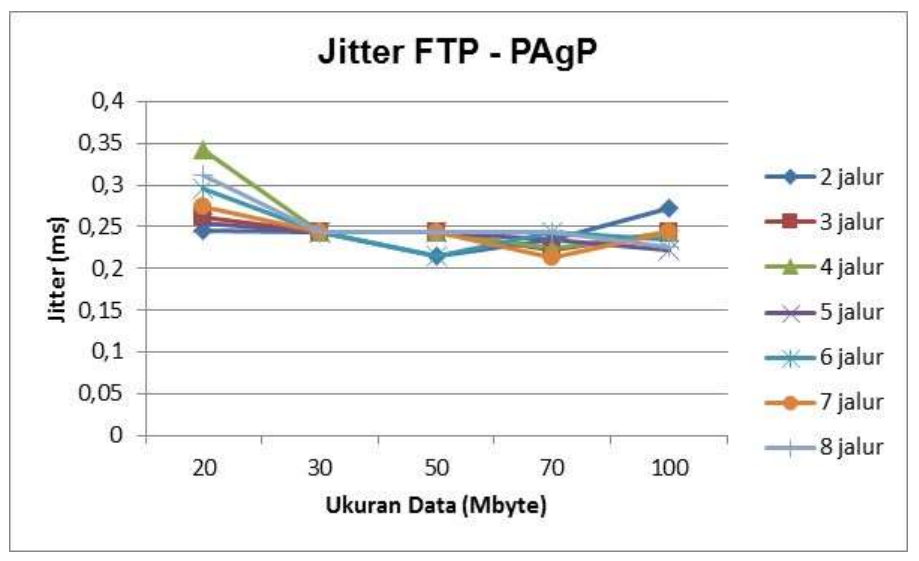

Gambar 8. Jitter layanan transfer file PAgP

Nilai delayakan berkaitan dengan nilai jitter. Waktu paket bisa sampai ke perangkat penerima berhubungan dengan interval waktu antar kedatangan paket. Gambar 8 menjelaskan hasil dari pengujian nilai jitter. Dari grafik yang ditunjukkan pada Gambar 8 terlihat bahwa nilai jitter relatif sama walaupun dengan memperbesar ukuran data atau menambah jumlah jalur yang digabung. Secara konsep dengan menambah jumlah jalur, maka dimungkinkan nilai jitterakan menurun. Hal ini dikarenakan adanya peningkatan kecepatan transfer data dengan menambah jumlah jalur. Namun berdasarkan keterangan topologi jaringan pada Gambar 1, bandwidth yang diberikan oleh jaringan trunk dengan menggunakan konsep link-aggregation tidak sesuai dengan bandwidth yang tersedia pada jalur akses yaitu hubungan antara perangkat switch dengan komputer. Walaupun jumlah link (jalur) pada jalur trunk ditambah, namun jumlah link pada jalur akses tetap satu jalur, dimana tipe Ethernet yang digunakan pada perangkat komputer dan switch adalah FastEthernet dengan ukuran bandwidth secara teori adalah 100 Mbps.

Dengan memperbesar ukuran data, jumlah paket yang dikirimkan juga semakin besar. Hal ini dikarenakan adanya proses segmentasi sebelum data bisa dikirimkan lewat jaringan. Dengan menggunakan teori ini, dapat disimpulkan bahwa nilai jittertidak dipengarahui oleh perubahan ukuran data, namun dapat dipengaruhi oleh penggunan konsep link-aggregation. Gambar 8 menjelaskan bahwa dengan memperbesar ukuran data, nilai jitteryang dihasilkan relatif stabil. Misalnya pada penggunaan 3 jalur untuk proses link-aggregation diperoleh nilai jitter rata-rata yaitu sebesar 0,243 ms. Gambar 8 juga menjelaskan adanya penurunan nilai jitter disaat digunakan ukuran data 70 Mbyte, namun dengan selisih perubahan nilai yang tidak terlalu besar dengan penggunaan ukuran data 50 Mbyte yaitu 0,022 ms. Masalah ini dikarenakan 
adanya ketidaksesuaian ukuran bandwidth antara jalur trunk dengan akses. Sehingga menyebabkan adanya delay processing pada perangkat switch.

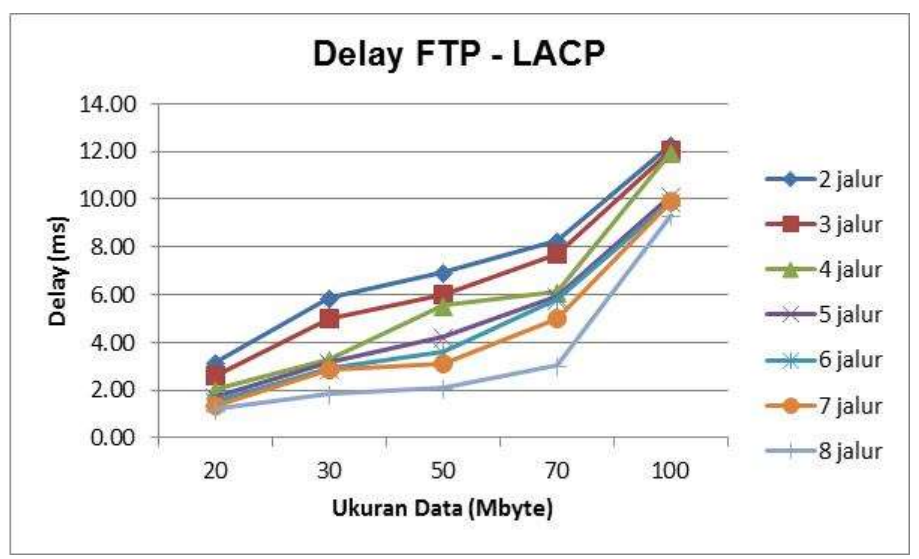

Gambar 9. Delay layanan transfer file LACP

Gambar 9 di atas merupakan hasil pengukuran nilai delay pada saat digunakan protokol LACP. Tren grafik perubahan ukuran file terhadap nilai delay juga sama seperti penggunaan protokol PAgP, namun dengan nilai yang berbeda. Sebagai contoh pada penggunaan ukuran file 20 Mbyte dan jalur yang digabungkan sebanyak 8 jalur. Pada penggunaan protokol PAgP, nilai delay yang dihasilkan adalah 2,232 ms. Sedangkan pada penggunaan protokol LACP sebesar $3,173 \mathrm{~ms}$. Hal ini terlihat bahwa penggunaan protokol LACP menghasilkan nilai delay yang relatif lebih besar dibandingkan penggunaan protokol PAgP. Begitupula ketika besaran data yang dipertukarkan sebesar 100 Byte. Penggunaan protokol PAgP menghasilkan nilai delay 11,176 ms, sedangkan LACP menghasilkan nilai delay sebesar 12,262 ms. Hasil pengukuran nilai delay tersebut apabila dilihat dari tabel standarisasi yang dikeluarkan oleh ITU-T masih dalam kategori baik (0 - $150 \mathrm{~ms})$.

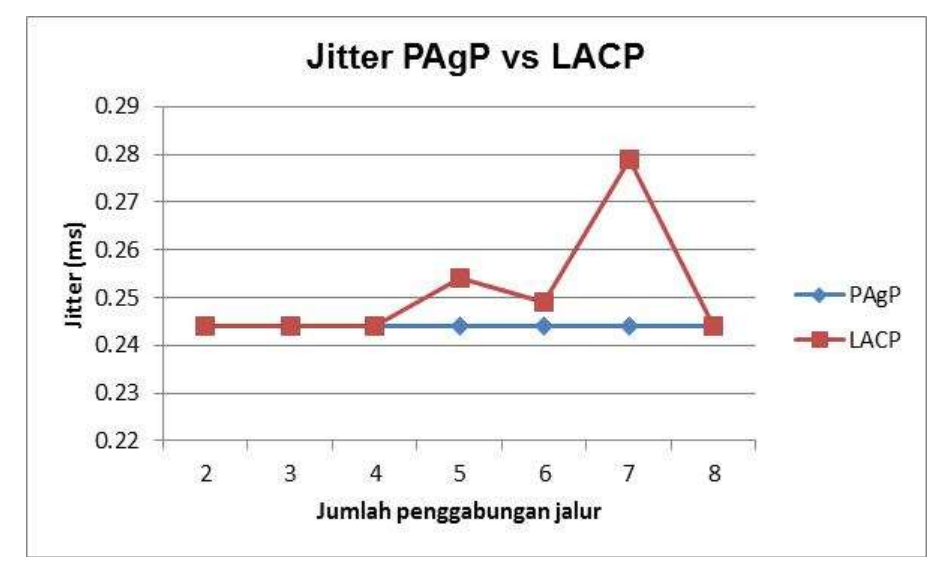

Gambar 10. Perbandingan rata-rata jitter PAgP dan LACP

Perbandingan nilai jitter ketika digunakan protokol PAgP dengan LACP dijelaskan pada keterangan Gambar 10. Grafik nilai jitter yang ditampilkan pada keterangan gambar tersebut merupakan nilai jitter dari hasil proses pengujian dengan menggunakan ukuran data sebesar 30 Mbyte dan jumlah pengujian sebanyak tiga puluh kali percobaan. Data grafik dari hasil pengujian memperlihatkan bahwa penggunaan protokol LACP menghasilkan nilai jitter yang relatif lebih besar dibandingkan ketika menggunakan protokol PAgP. Perbedaan nilai jitter mulai terlihat ketika digunakan jumlah jalur yang digabungkan sebesar 5 jalur. Penggunaan 
protokol PAgP menghasilkan nilai jitter sebesar 0,244 $\mathrm{ms}$, sedangkan nilai jitter disaat menggunakan protokol LACP sebesar 0,254 ms. Perbedaan nilai tersebut relatif kecil. Perbedaan deviasi nilai jitter terbesar terjadi pada saat digunakan 7 jalur yang digabung. PAgP menghasilkan nilai jitter sebesar 0,244 ms, sedangkan LACP menghasilkan nilai yang lebih besar yaitu 0,279 ms. Grafik nilai jitter ketika digunakan protokol PAgP relatif konstan yaitu di angka 0,244 ms. Artinya pada pengujian sebanyak tiga puluh kali percobaan dihasilkan nilai rata-rata jitter yaitu sebesar 0,244 ms. Berbeda dengan nilai rata-rata jitter ketika digunakan protokol LACP yaitu 0,251 ms. Nilai jitter ketika digunakan protokol PAgP cenderung konstan, sedangkan pada penggunaan protokol LACP cenderung tidak stabil. Namun perbedaan nilai jitter tersebut relatif tidak terlalu besar. Ketidakstabilan nilai jitter disaat digunakan protokol LACP lebih disebabkan karena ketidaksesuaian antara protokol dengan perangkat uji yang digunakan. LACP adalah protokol yang dibuat oleh IEEE, sedangkan PAgP adalah protokol yang dibuat oleh Cisco. Pada saat melakukan proses pengujian, perangkat switch yang digunakan adalah produk dari Cisco. Dari hasil pengujian nilai jitter untuk layanan FTP terlihat bahwa switch produk dari Cisco hanya cocok dengan protokol produk dari Cisco untuk proses link-aggregation yaitu PAgP.

\subsubsection{Layanan Video Streaming}

Layanan berikutnya yang diujikan adalah video streaming. Pengambilan data streaming dimulai dari komputer client ke server yang memanfaatkan software VLC. Pengukuran nilai delay masih menggunakan software Wireshark. Pengambilan data dilakukan pada komputer client. File video berukuran 70 Mbyte dijalankan pada komputer server, kemudian diakses oleh komputer client.



Gambar 11. Perbandingan delay layanan video streaming

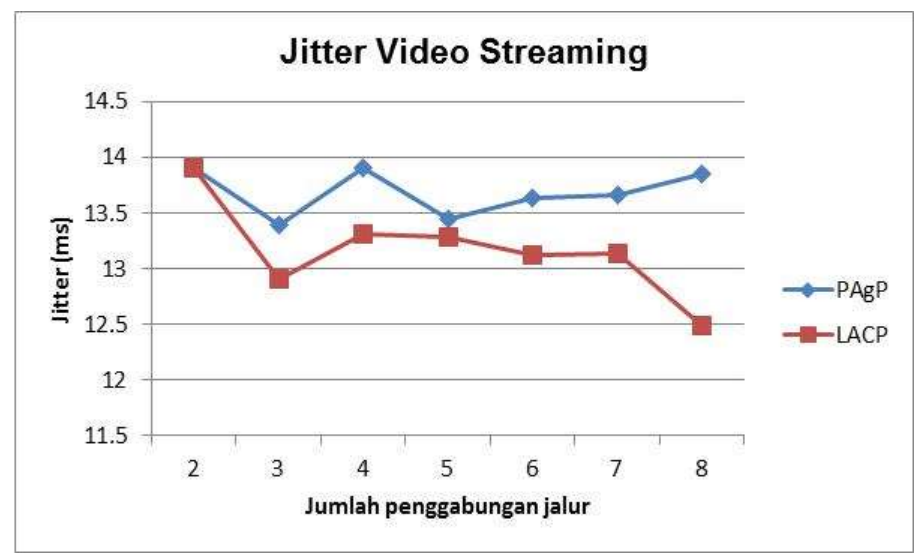

Gambar 12. Perbandingan jitter layanan video streaming 
Pengujian delay dan jitter untuk layanan video streaming hanya dilakukan pada satu ukuran data yaitu 70 Mbyte. Gambar 11 di atas menjelaskan hasil pengujian delay ketika digunakan protokol PAgP dan LACP. Jumlah jalur yang digabungkan dimulai dari 2 jalur, 3 jalur, sampai 8 jalur. Pada pengujian menggunakan dua jalur, penggunaan protokol PAgP menghasilkan nilai delay yang lebih kecil dibandingkan dengan LACP. Nilai delay yang dihasilkan oleh PAgP sebesar 49,685 ms, sedangkan LACP menghasilkan nilai delay sebesar 49,834 ms. Pada pengujian berikutnya dengan menggunakan 3 jalur yang digabungkan, nilai delay LACP sedikit lebih kecil dibandingkan dengan nilai delay dari PAgP. LACP menghasilkan nilai delay 49,857 ms, sedangkan nilai delay yang dihasilkan oleh PAgP sebesar 49,818 ms. Pada pengujian kedua dengan menggunakan 3 jalur yang digabung tersebut masih belum diketahui tren grafik yang menunjukkan apakah penggunaan protokol PAgP lebih baik dari LACP begitupula sebaliknya. Namun pada pengujian ketiga dan keempat dengan menggunakan 4 dan 5 jalur yang digabung diketahui adanya tren grafik yang menunjukkan bahwa penggunaan protokol PAgP menghasilkan nilai delay yang lebih kecil dibandingkan dengan LACP. Tren grafik mulai terlihat pada penggunaan 3 sampai 5 jalur yang digabung yaitu cenderung menurun. Akan tetapi pada penggunaan protokol PAgP, tren grafik mulai naik saat digunakan 6 jalur yang digabung. Berbeda dengan menggunakan protokol LACP yang masih dalam tren menurun dan mulai naik saat digunakan 7 jalur yang digabung. Hal ini memperlihatkan adanya anomali tren grafik hasil pengujian dari keterangan Gambar 11. Penyebab utama kejadian tersebut adalah adanya ketidaksesuaian nilai bandwidth antara jalur utama, dalam hal ini adalah jalur trunk dengan jalur akses yang menghubungkan perangkat switch dengan komputer. Nilai bandwidth yang digunakan pada jalur akses adalah sebesar $100 \mathrm{Mbps}$ dengan menggunakan tipe FastEthernet, sedangkan kalau jumlah jalur yang digabung sebesar 5 jalur, maka akan menghasilkan nilai bandwidth pada jalur trunk sebesar 5 x 100 Mbps (500 Mbps). Hal ini terjadi perbedaan nilai bandwidth yang sangat besar antara jalur trunk dengan jalur akses. Akibat kejadian ini maka terjadi penumpukan jumlah antrian paket pada perangkat switch sebelum paket tersebut dikirimkan ke komputer penerima lewat jalur akses. Dalam jaringan komputer istilah ini dinamakan dengan bottleneck. Perbedaan nilai bandwidth yang besar antara jalur trunk dengan jalur akses menyebabkan adanya delay processing pada perangkat switch. Delay processing juga akan menambah nilai delay end-to-end antara perangkat komputer pengirim dan penerima.

Dari penjelasan grafik pada Gambar 11 memperlihatkan bahwa adanya batasan optimal penggunaan jumlah jalur yang digabung jika dilihat dari sisi parameter delay. Misalnya pada penggunaan protokol PAgP, jumlah optimal jalur yang digabung adalah sebesar 5 jalur, sedangkan pada penggunaan protokol LACP adalah sebesar 6 jalur. Gambar 11 juga menjelaskan adanya perbedaan hasil nilai delay antara penggunaan protokol PAgP dan LACP dilihat dari sisi peningkatkan performansi jaringan. Pada saat digunakan protokol PAgP, nilai delaycenderung mulai menurun pada saat digunakan penggabungan 3 jalur dan mulai kembali naik saat digunakan 6 jalur yang digabung. Berbeda dengan penggunaan protokol LACP. Nilai delay mulai turun disaat digunakan 4 jalur yang digabung dan mulai naik saat digunakan 7 jalur yang digabung. Adanya perbedaan nilai ini memperlihatkan respon perbaikan performansi jaringan protokol PAgP lebih baik dibandingkan LACP. Namun demikian hasil pengujian terlihat berbeda pada penggunaan parameter jitter seperti yang terlihat keterangan grafik pada Gambar 12. Pengujian dengan menggunakan 2 jalur, baik pada penggunaan protokol PAgP maupun LACP menghasilkan nilai jitter yang sama yaitu 13,907 ms. Namun apabila dilihat pada keseluruhan hasil pengujian dengan jumlah jalur yang digabungkan berbeda-beda, terlihat bahwa nilai jitter pada saat menggunakan protokol LACP masih lebih kecil dibandingkan jika digunakan protokol PAgP. 


\subsection{Pengujian Parameter Throughput \\ 3.2.1 Layanan File Transfer}

Selain delay, parameter lain yang diujikan adalah throughput. Perhitungan nilai throughput masih menggunakan software wireshark. Jumlah total ukuran dari paket yang dikirim dibagi dengan waktu pengiriman paket. Hal ini sesuai pada penjelasan perhitungan nilai throughput pada Persamaan (4). Layanan awal yang digunakan adalah proses transfer file dengan memanfaatkan protokol FTP.



Gambar 13. Hasil perhitungan nilai throughput FTP

Proses transfer file dalam jaringan digunakan protokol PAgP. Jumlah jalur yang digabungkan sama seperti pada saat melakukan pengujian dengan menggunakan parameter delay. Penggabungan jalur dimulai dari 2 jalur sampai 8 jalur. Sesuai pada keterangan Gambar 13, nilai throughput akan semakin besar dengan semakin banyak jumlah jalur yang digabungkan. Dari hasil pengujian terlihat bahwa penggabungan jumlah jalur sangat memberikan dampak yang positif dalam hal performansi jaringan. Konsep penggabungan jalur yang dilakukan oleh protokol PAgP terbukti dapat meningkatkan nilai throughputbagi end-user. Misalnya pada saat penggunaan ukuran data 20 Mbyte. Penggunaan 2 jalur dalam melakukan proses load balancing memberikan nilai throughput sebesar 7,253 Mbps. Sedangkan ketika jalur yang digabungkan menjadi 8 jalur, nilai throughput yang didapatkan oleh komputer client sebesar 11,179 Mbps.



Gambar 14. Perbandingan nilai throughput PAgP dan LACP

Perhitungan nilai throughput juga bisa dibandingkan hasilnya ketika protokol yang digunakan adalah LACP. Gambar 14 di atas menjelaskan perbandingan hasil pengukuran nilai throughput, 
dimana ukuran data yang digunakan hanya 50 Mbyte. Proses pengujian tidak dilakukan pada semua ukuran data. Hasil pengujian memperlihatkan bahwa tidak adanya kestabilan nilai. Grafik nilai throughput pada keterangan Gambar 14 memperlihatkan penggunaan protokol PAgP memberikan nilai throughput yang lebih baik dibandingkan jika menggunakan LACP. Hal ini bisa dilihat pada penggunaan jalur yang digabungkan sebanyak 2, 3, 5, 6, dan 7 jalur. Namun pada penggunaan penggabungan jalur tertentu terdapat hasil yang berbeda. Pada penggabungkan 4 dan 8 jalur, penggunaan protokol LACP menghasilkan nilai throughputyang relatif lebih baik jika dibandingkan dengan PAgP. Namun dari tren grafik perbandingan nilai throughput pada keterangan Gambar 14 memperlihatkan bahwa penggunaan protokol PAgP masih memberikan nilai throughput yang lebih baik dibandingkan dengan penggunaan protokol LACP.

\subsubsection{Layanan Video Streaming}

Pengukuran parameter throughput dengan menggunakan layanan video streaming masih dilakukan pada sisi komputer client. Terdapat file yang berisi video diakses oleh komputer client. Ukuran resolusi dari video yang digunakan dalam proses pengujian adalah sebesar 360p. Agar komputer client bisa mengakses file video dari server, software VLC diaktifkan baik pada sisi komputer client maupun server.

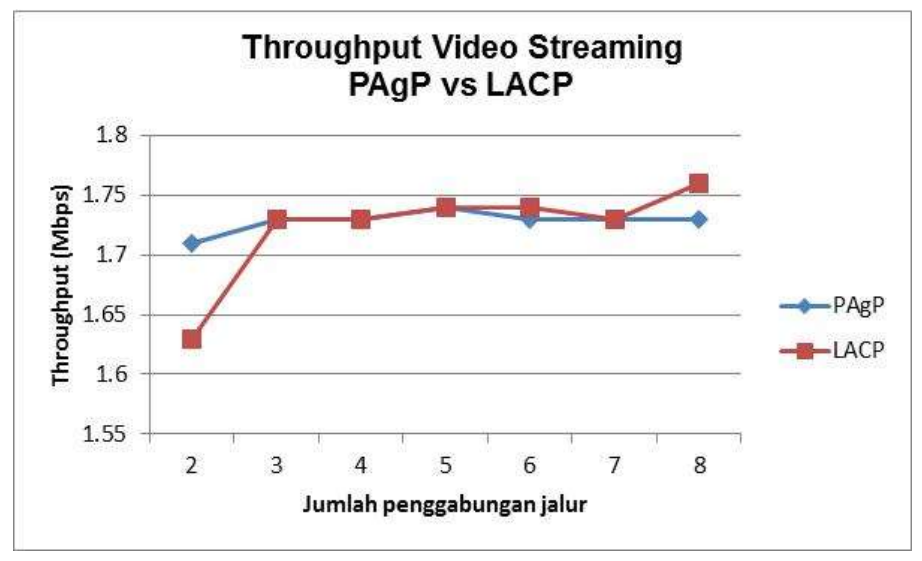

\section{Gambar 15. Hasil nilai throughput untuk layanan video streaming}

Gambar 15 menjelaskan hasil perbandingan nilai throughput ketika jaringan diaktifkan teknologi EtherChannel dengan menggunakan protokol PAgP dan LACP. Ukuran file dari video yang ditelakkan di sisi komputer server adalah sebesar 70 Mbyte. File tersebut kemudian diakses oleh komputer clientdengan menggunakan bantuan software VLC. Software Wireshark juga diaktifkan pada sisi komputer client untuk menghitung nilai throughput. Perhitungan nilai throughput sendiri menggunakan Persamaan (4).

Grafik yang ditunjukkan pada keterangan Gambar 15 di atas memperlihatkan bahwa belum terjadi konsistensi nilai antara ketika digunakan protokol PAgP maupun LACP. Pengujian dilakukan dengan menambahkan jumlah jalur yang digabungkan pada jalur trunk. Pada pengujian dengan menggunakan 2 jalur, nilai throughput ketika digunakan protokol PAgP menghasilkan nilai yang lebih besar dibandingkan dengan ketika digunakan protokol LACP. Pada pada pengujian dengan menggunakan 3, 4, 5, 6, dan 7 jalur dihasilkan nilai throughput yang relatif sama yaitu dengan rata-rata nilai throughput sebesar 1,73 Mbps. Namun jika dilihat dari tren hasil nilai throughput yang dihasilkan pada keterangan Gambar 15 di atas terlihat bahwa penggunaan protokol PAgP menghasilkan nilai throughput dengan tren nilai yang relatif lebih stabil dibandingkan dengan ketika digunakan protokol LACP yaitu di angka 1,73 Mbps. Sehingga jika dilihat dari tingkat kestabilan nilai throughput untuk penggunaan 
layanan video streaming, penggunaan protokol PAgP masih lebih baik dibandingkan dengan penggunaan protokol LACP.

\section{KESIMPULAN}

Berdasarkan hasil pengujian jaringan dengan memanfaatkan teknologi EtherChannel dengan menggunakan protokol PAgP dan LACP diperoleh hasil bahwa penggunaan teknologi tersebut mampu meningkatkan performansi jaringan jika dilihat dari parameter delay, jitter, dan throughput. Pada implementasi layanan FTP, penggunaan protokol PAgP masih lebih baik dibandingkan dengan protokol LACP, baik dilihat dari parameter delay, jitter, maupun throughput. Namun berbeda hasilnya pada penggunaan layanan video streaming. Penggunaan protokol PAgP memberikan performansi jaringan yang lebih baik dibandingkan dengan LACP hanya dilihat dari sisi parameter delay dan throughput, namun hasil pengujian berbeda ketika digunakan parameter jitter. Sehingga dari hasil pengujian dapat disimpulkan bahwa penggunaan teknologi EtherChannel pada perangkat switch produk dari Cisco hanya cocok menggunakan protokol buatan Cisco yaitu PAgP. Penggunaan protokol tersebut mampu memberikan peningkatan performansi jaringan yang lebih baik dibandingkan jika digunakan protokol LACP. Namun perlu adanya penelitian lebih lanjut jika perangkat switch yang digunakan adalah bukan produk dari Cisco.

\section{DAFTAR RUJUKAN}

Komputer, W. (2012). Optimalisasi Jaringan Komputer Kabel \& Nirkabel. Yogyakarta: Andi Publisher.

Nugroho, K. (2017). Switch \& Multilayer Switch Cisco. Bandung: Informatika.

Tulloh, R. (2017). Analisis Performansi Agregasi Link Dengan LACP Pada SDN Menggunakan Ryu Sebagai Controller. Jurnal Nasional Teknik Elektro, 6(3), 203-213.

Amin, Z. (2014). Simulasi dan Perancangan Keamanan Autentikasi Jaringan Hirarki Link Aggregation Control Protocol (LACP) Berbasis Router Cisco (Studi Kasus: STMIK PALCOMTECH). Konfrensi Nasional Teknologi Informasi dan Aplikasinya, (pp. 9-17).

SysKonnect. (2002). Link Aggregation according to IEEE Standard 802.3ad. White Paper.

Djomi, M. M. (2018). Analisis Performansi Layanan FTP dan Video Streaming berbasis Network Function Virtualization menggunakan Docker Containers. ELKOMIKA, 6(2), 180-193.

Community, C. S. (2007, July 9). Understanding EtherChannel Load Balancing and Redundancy on Catalyst Switches. Dikutip dari https://www.cisco.com/c/en /us/support/docs/lanswitching/etherchannel/12023-4.html

Nugroho, K. (2017). Uji Performansi Jaringan Menggunakan Kabel UTP dan STP. ELKOMIKA, 5(1), 48-59.

Forouzan, B. A. (2013). Data Communications and Networking 5E, Fifth Edition. United States: McGraw-Hill.

ITU-T. (2003, May). Series G: Transmission Systems and Media, Digital Systems and Networks (One-way transmission time). Dikutip dari https://www.itu.int/rec/T-REC-G.114/en. 